\title{
Effect of annealing time on the structural, morphological, optical and electrical properties of NiS thin films
}

\author{
A. Gahtar ${ }^{\mathrm{a}, \mathrm{b}, *}$, A. Benali ${ }^{\mathrm{a}}, \mathrm{S}$. Benramache ${ }^{\mathrm{b}}$, C. Zaouche $^{\mathrm{b}}$ \\ ${ }^{a}$ Department of biology, Faculty of sciences, University Elchahid Hamma \\ Lakhder, 39000 El Oued, Algeria \\ ${ }^{b}$ Material Sciences Department, Faculty of Sciences, University of Biskra, 07000, \\ Algeria
}

\begin{abstract}
In this work, we prepared thin films of nickel sulfide by spray pyrolysis on substrates of the glass at temperature of $300^{\circ} \mathrm{C}$. The solution used is a mixture of nickel acetate and thiourea as a source of nickel and sulfur respectively, acetic acid was used as a complexing agent, and then heated the resulting layers in an ordinary furnace at $300^{\circ} \mathrm{C}$ at different times of $1 \mathrm{~h}, 2 \mathrm{~h}$ and $3 \mathrm{~h}$ to study the annealing time effect on the physical and chemical properties. The characterization methods used indicate remarkable changes in the structural, electrical, morphological and optical properties of NiS films under annealing time. The results obtained have shown that the prepared NiS films contain good crystallization, dense morphology, good stochiometric ratio and high conductivity, and these specifications make them a potential candidate as electrode material for application in super-capacitors.
\end{abstract}

(Received November 7, 2021; Accepted February 11, 2022)

Keywords: Nickel sulfide, spray-pyrolysis, Annealing time, DRX, SEM\&EDS

\section{Introduction}

Nickel sulfide is the most attractive material since it has high electron mobility, a good reflection in the infrared range, an ease of production and low toxicity. As one of the main classes of transition metals, Chalcogénures, nickel sulfides exist in different phases, such as $\mathrm{NiS}, \mathrm{NiS}_{2}$, $\mathrm{Ni}_{3} \mathrm{~S}_{2}, \mathrm{Ni}_{7} \mathrm{~S}_{6}$ and $\mathrm{Ni}_{9} \mathrm{~S}_{8}$. Among these phases, $\mathrm{NiS}$ exhibits an excellent capacity performance, high redox activity, which should satisfy the growing need for energy storage systems [1]. Scientists think that this material is important and challenging. Generally, NiS exists in two phases, hexagonal and rhombohedral [2]. Both phases exhibit a many applications. Different methods such as spray pyrolysis [3] the deposition of the chemical bath (CBD) [4], hydrothermal [5], adsorption and reaction of successive ionic layer (SILAR)[6], thermal evaporation [7], electro-deposition [8] and sol-gel [9] have deposited the thin films of NiS. Since thin films are very important in industrial production, an easy and inexpensive method should be sought among the methods which have proven to be effective are the spray pyrolysis method, because they do not require advanced technologies and complex devices, but they need simple devices and access to films at low cost. These films deposited in this way are characterized by their strong adhesion to the substrate, the ability to prepare a film with surfaces relatively large and the ability to obtain films with the required specifications, and this is done by mixing a solution of two or more materials and changing the proportions involved in the composition of the film.

In this article, we describe the preparation method, the experimental details and techniques that describe the layers deposited with NiS. Then we discuss the results obtained of the prepared NiS. Finally, a summary of the research will be given and prospects for future research will be discussed.

\footnotetext{
*Corresponding author: abdelouahab-gahtar@univ-eloued.dz https://doi.org/10.15251/CL.2022.192.103
} 


\section{Experimental details}

\subsection{Preparation of nickel sulfide NiS films}

We used nickel sulfide NiS films prepared by pyrolysis spraying on glass substrates, nickel acetate $\left(\left(\mathrm{C}_{4} \mathrm{H}_{6} \mathrm{O}_{4} \mathrm{Ni} .4 \mathrm{H}_{2} \mathrm{O}\right), 0.07 \mathrm{~mol} / \mathrm{l}\right)$ was used as a source of $\mathrm{Ni}$, thiourea $\left(\mathrm{CS}\left(\mathrm{NH}_{2}\right)_{2}\right.$, $0.21 \mathrm{~mol} / \mathrm{l}$ ) was used as a source of $\mathrm{S}$ and acetic acid was used as a complexing agent. The cleaned glass substrates were heated to $(300 \pm 5){ }^{\circ} \mathrm{C}$ on a hot plate. The distance between the nozzle and the substrate was chosen at $40 \mathrm{~cm}$ and air pressure of 0.5 bar was used as carrier gas, the flow rate of the solution was adjusted to $10 \mathrm{ml} / \mathrm{min}$. using a flow meter and the atomization process was completed in about 15 minutes. In addition to pure NiS, we prepared series of thin film NiS annealed in an ordinary furnace at temperature $\operatorname{Tr}=300{ }^{\circ} \mathrm{C}$ with different annealing times of $1 \mathrm{~h}, 2 \mathrm{~h}$ and $3 \mathrm{~h}$.

One of the initial fundamental steps needed to reduce the potential site for interface recombination in thin films is to ensure the use of clean substrates for deposition. In this study, soda lime glass slides with the dimensions: $76 \mathrm{~mm} \times 26 \mathrm{~mm}$, were used as substrates. The soda lime glasses were first cleaned using detergent and with distilled water. Further, the glass substrates were then cleaned ultrasonically for 15 minutes, followed by a rinse with acetone and the glass substrates were then dried by using nitrogen gas. Our study focused on four types of samples presented in Table1.

Table 1. Symbols of the different NiS films prepared by the technique of the spray pyrolysis on glass substrates at $300{ }^{\circ} \mathrm{C}$ then heat treatment at $300{ }^{\circ} \mathrm{C}$ in an ordinary oven at different times $1 \mathrm{~h}, 2 \mathrm{~h}$ and $3 \mathrm{~h}$.

\begin{tabular}{|l|l|}
\hline Samples & Film preparation conditions \\
\hline (a): $0 \mathrm{~h}$ & Thin film of NiS deposited by spray pyrolysis at $300^{\circ} \mathrm{C}$ not annealed \\
\hline (b): $1 \mathrm{~h}$ & $\begin{array}{l}\text { Thin film of NiS deposited by spray pyrolysis at } 300^{\circ} \mathrm{C} \text { and heat } \\
\text { treated in an oven at } 300^{\circ} \mathrm{C} \text { for } 1 \text { hour }\end{array}$ \\
\hline (c): $2 \mathrm{~h}$ & $\begin{array}{l}\text { Thin film of NiS deposited by spray pyrolysis at } 300^{\circ} \mathrm{C} \text { and heat } \\
\text { treated in an oven at } 300^{\circ} \mathrm{C} \text { for } 2 \text { hour }\end{array}$ \\
\hline (d): $3 \mathrm{~h}$ & $\begin{array}{l}\text { Thin film of NiS deposited by spray pyrolysis at } 300^{\circ} \mathrm{C} \text { and heat } \\
\text { treated in an oven at } 300^{\circ} \mathrm{C} \text { for } 3 \text { hour }\end{array}$ \\
\hline
\end{tabular}

The film thickness was estimated using the weight method, which yields the thickness according to the formula [10]:

$$
e=\frac{m}{\rho * S}
$$

where $e$ is the film thickness, $m$ the mass deposited onto substrate, $S$ the area of the film and $\rho$ is the density of $\mathrm{NiS}\left(5.50 \mathrm{~g} / \mathrm{cm}^{3}[11]\right)$.

\subsection{Characterization techniques}

The thin films obtained NiS unannealed and annealed $1 \mathrm{~h}, 2 \mathrm{~h}$ and $3 \mathrm{~h}$ were characterized by: Phase compositions of the films were obtained from the data of the X-ray diffractograms (XRD) using X-ray diffraction analysis (Bruker/D8). $\mathrm{Cu} \mathrm{K} \alpha$ radiation target of wavelength 0.154 $\mathrm{nm}$ was employed in the $2 \theta$ range from $20^{\circ}$ to $60^{\circ}$ at room temperature. A dual-beam UV-visible spectrophotometer (UV-3101; Shimadzu), was used to measure the transmittance and reflectance in the wavelength range of $300-1100 \mathrm{~nm}$ with a resolution of $5 \mathrm{~nm}$. The surface morphology was analyzed using an electron microscopy scanning (SEM; Qanta 350) equipped with an energy dispersive spectrometer (EDS) for elementary analysis. The type of chemical bonds present in the samples was identified using an infrated transmission spectrometer (FTIR; Shimadzu, model IR 
Affinity-1) in the range of $400-4000 \mathrm{~cm}^{-1}$. The electrical measurements were recorded using the four-probe method.

\section{Results and discussion}

\subsection{X-Ray Diffraction}

Fig. 1 shows the X-ray diffraction (XRD) spectra of unannealed and annealed $1 \mathrm{~h}, 2 \mathrm{~h}$ and $3 \mathrm{~h} \mathrm{NiS}$ samples deposited on glass substrates by the spray pyrolysis technique at temperatures of $300^{\circ} \mathrm{C}$.

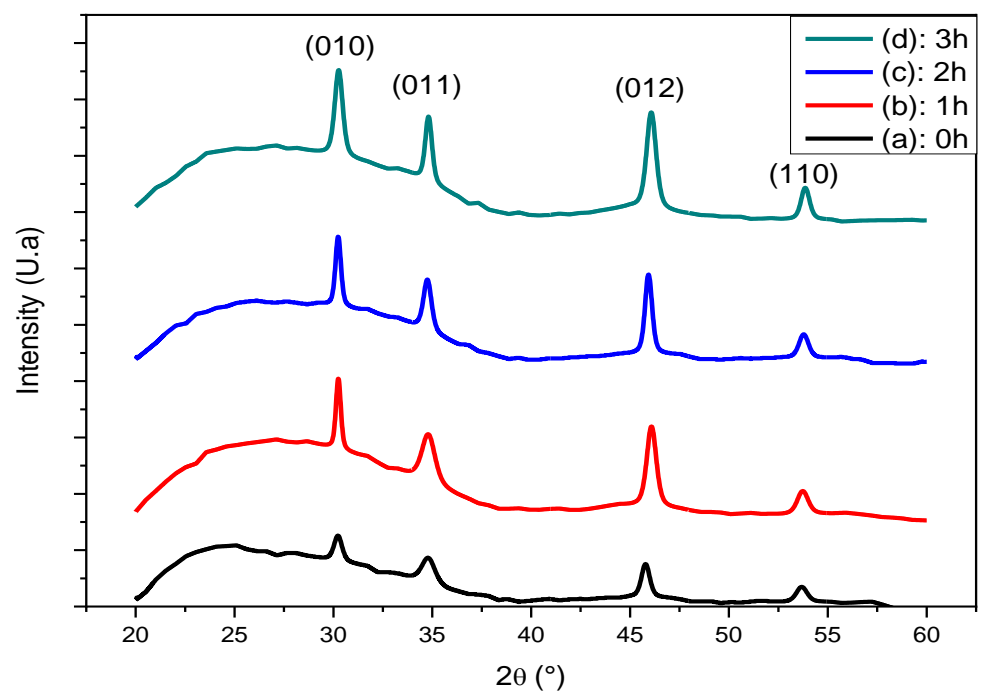

Fig. 1. DRX spectra of the NiS films: (a): Oh, $(b): 1 h,(c): 2 h$ and $(d): 3 h$.

The DRX spectra show that all the thin films obtained are polycrystalline and have a hexagonal structure strongly oriented in the (012) directions, on the unannealed and annealed NiS spectrum we notice the presence of diffraction peaks corresponding respectively to the : (010); (011); (012); (110) of polycrystalline NiS of hexagonal structure (JCPDS card \# 98-064-6340). We also note that the peaks are slightly offset from the positions shown on the ASTM Data Sheet. This shift is probably due to stresses that deform the mesh, which has led to changes in the mesh parameters that more or less shift the position of the peaks as shown in Table 3. On the other side of the coin, the data obtained in this study are also in a good agreement with the previous reports in the literature on NiS films prepared by spray-pyrolysis and other techniques [3, 12, 13].

The unit cell parameters $\mathrm{a}, \mathrm{b}$ and $\mathrm{c}$, were determined using the following formula [14]:

$$
\frac{1}{\mathrm{~d}_{\mathrm{hkl}}^{2}}=\frac{3}{4}\left(\frac{\mathrm{h}^{2}+\mathrm{k}^{2}+\mathrm{hk}}{\mathrm{a}^{2}}\right)+\frac{\mathrm{l}^{2}}{\mathrm{c}^{2}}
$$

The unit cell volume was evaluated using the following formula:

$$
V=a^{2} \times c \times \sin \left(60^{\circ}\right)
$$


Table 2. Lattice parameters ( $a, b$ and $c)$ and the unit cell volume V compared to those values of the JCPDS card \#98-064-6340.

\begin{tabular}{|c|c|c|c|c|c|c|c|}
\hline \multirow{2}{*}{$\begin{array}{c}\text { Annealing } \\
\text { time }\end{array}$} & \multicolumn{5}{|c|}{ Latice parameters } & \multirow{2}{*}{$\begin{array}{c}\text { Unit cell volume } \\
\left(\AA^{3}\right)\end{array}$} \\
\cline { 2 - 5 } & $\mathrm{a}=\mathrm{b}(\AA)$ & $\mathrm{c}(\AA)$ & $\mathrm{c} / \mathrm{a}$ & $\mathrm{a}=\mathrm{b}(\AA)$ & $\mathrm{c}(\AA)$ & $\mathrm{c} / \mathrm{a}$ & \\
\hline (a): $0 \mathrm{~h}$ & 3.416 & 5.275 & 1.544 & \multirow{3}{*}{3.420} & \multirow{2}{*}{5.300} & \multirow{2}{*}{1.550} & 52.936 \\
\hline (c): $1 \mathrm{~h}$ & 3.411 & 5.284 & 1.549 & & 52.871 \\
\hline (d): $2 \mathrm{~h}$ & 3.413 & 5.266 & 1.542 & & & & 52.753 \\
\hline (b): $3 \mathrm{~h}$ & 3.413 & 5.282 & 1.547 & & & & 52.913 \\
\hline
\end{tabular}

Table 2 resumes the obtained values of the structural parameters compared to those of the corresponding JCPDS card. It is observed that the reported values of the films are very close to each others. Furthermore, the unit cell volume decreases with the increase in the annealing time, owing to an improved crystal growth in the films [14]. This phenomenon shows that the annealing of the resulting layers has an essential role in the improvement of optical quality and electrical properties [15]. Table 3 summarizes the inter-plans distances determined from the XRD patterns. The observed mismatch between the inter-plans distances indicates the formation of strained lattice with the development of micro-stress during crystallization of the films.

The inter-plans distance $\left(\mathrm{d}_{\mathrm{hkl}}\right)$ was calculated by Bragg formula $[16,17]$ :

$$
2 d d_{h k l} \sin \theta=n \lambda
$$

Table 3. Inter-planar distances $\left(d_{h k l}\right)$ of NiS thin films.

\begin{tabular}{|c|c|c|c|c|}
\hline Annealing time & (a): $0 \mathrm{~h}$ & (c): $1 \mathrm{~h}$ & $(\mathrm{~d}): 2 \mathrm{~h}$ & $(\mathrm{~b}): 3 \mathrm{~h}$ \\
\hline $\mathrm{d}_{010}(\AA)$ & 2,959 & 2,957 & 2,958 & 2,955 \\
\hline $\mathrm{d}_{011}(\AA)$ & 2,580 & 2,580 & 2,583 & 2,579 \\
\hline $\mathrm{d}_{012}(\AA)$ & 1,983 & 1,971 & 1,977 & 1,972 \\
\hline $\mathrm{d}_{110}(\AA)$ & 1,709 & 1,707 & 1,706 & 1,703 \\
\hline
\end{tabular}

X-ray diffraction spectra were exploited to determine the crystallites size $\mathrm{D}$, dislocation density $\delta$ and stresses $\varepsilon$ in NiS films.

Firstly, The crystallite size $\left(D_{\text {hkl }}\right)$ was estimated for all diffraction peaks using Scherer formula [18]:

$$
D_{h k l}=\frac{k \lambda}{\beta_{1 / 2} \cos \theta}
$$

where: $k$ is a constant $(k=0.90), \beta_{1 / 2}$ the full width at half maximum of the diffraction peak, $\theta$ is the Bragg angle and $\lambda=1.5406 \AA$ is the wavelength of the $\mathrm{X}$-ray radiation used.

Table 4. The crystallites size $\left(\mathrm{D}_{\mathrm{hkl}}\right)$ of NiS thin films.

\begin{tabular}{|c|c|c|c|c|}
\hline Annealing time & (a): $0 \mathrm{~h}$ & (c): $1 \mathrm{~h}$ & (d): $2 \mathrm{~h}$ & (b): $3 \mathrm{~h}$ \\
\hline $\mathrm{D}_{010}(\mathrm{~nm})$ & 18,680 & 32,025 & 28,018 & 18,682 \\
\hline $\mathrm{D}_{011}(\mathrm{~nm})$ & 11,338 & 11,338 & 18,896 & 22,678 \\
\hline $\mathrm{D}_{012}(\mathrm{~nm})$ & 19,573 & 16,796 & 23,500 & 16,795 \\
\hline
\end{tabular}




\begin{tabular}{|l|l|l|l|l|}
\hline $\mathrm{D}_{110}(\mathrm{~nm})$ & 15,154 & 15,157 & 17,329 & 20,223 \\
\hline
\end{tabular}

Secondly, The dislocation density $\left(\delta_{\mathrm{hkl}}\right)$, which measures the amount of defects in a crystal is defined by the length of dislocation lines per unit volume. We used the following formula in order to determine it $[10,13]$ :

$$
\delta_{h k l}=\frac{1}{D_{h k l}^{2}}
$$

Table 5. The dislocation density $\left(\delta_{h k l}\right)$ of NiS thin films.

\begin{tabular}{|c|c|c|c|c|}
\hline Annealing time & (a): $0 \mathrm{~h}$ & (c): $1 \mathrm{~h}$ & (d): $2 \mathrm{~h}$ & (b): $3 \mathrm{~h}$ \\
\hline$\delta_{010}\left(10^{15}\right.$ lines/ $\left.\mathrm{m}^{2}\right)$ & 2.872 & 0.975 & 1.271 & 2.875 \\
\hline$\delta_{011}\left(10^{15}\right.$ lines $\left./ \mathrm{m}^{2}\right)$ & 7.788 & 7.784 & 2.806 & 1.944 \\
\hline$\delta_{012}\left(10^{15}\right.$ lines/ $\left.\mathrm{m}^{2}\right)$ & 2.614 & 3.543 & 1.814 & 3.541 \\
\hline$\delta_{110}\left(10^{15}\right.$ lines $\left./ \mathrm{m}^{2}\right)$ & 4.351 & 4.351 & 3.337 & 2.456 \\
\hline
\end{tabular}

Finally, the microstrain $\left(\varepsilon_{\mathrm{hkl}}\right)$, was estimated using the following formula [19]:

$$
\varepsilon_{h k l}=\frac{\beta_{1 / 2}}{4 \tan \theta}
$$

Table 6. Micro-stress values $\left(\varepsilon_{\mathrm{hkl}}\right)$ of NiS thin films.

\begin{tabular}{|c|c|c|c|c|}
\hline Annealing time & (a): $0 \mathrm{~h}$ & (c): $1 \mathrm{~h}$ & (d): $2 \mathrm{~h}$ & (b): $3 \mathrm{~h}$ \\
\hline$\varepsilon_{010}\left(10^{-3}\right)$ & 7.636 & 4.451 & 5.089 & 7.626 \\
\hline$\varepsilon_{011}\left(10^{-3}\right)$ & 10.97 & 10.993 & 6.591 & 5.482 \\
\hline$\varepsilon_{011}\left(10^{-3}\right)$ & 4.885 & 5.657 & 4.056 & 5.659 \\
\hline$\varepsilon_{110}\left(10^{-3}\right)$ & 5.436 & 5.430 & 4.745 & 4.060 \\
\hline
\end{tabular}

Else ways, The texture coefficient $\left(\mathrm{TC}_{\mathrm{hkl}}\right)$, which is calculated in terms of the intensity of each orientation $\left(\mathrm{I}_{\mathrm{hk}}\right)$ to the correspending intensity of the JCPDS card $\left(\mathrm{I}_{0 \mathrm{hk}}\right)$, gives information on the probability of the growth according to an orientation [hkl]. The coefficient $\left(\mathrm{TC}_{\mathrm{hkl}}\right)$ is given by relation below [20]:

$$
T C_{h k l}=\frac{I_{h k l} / I_{0 h k l}}{N^{-1}\left(\sum_{i=1}^{n} \frac{I_{h k l}}{I_{0 h k l}}\right)}
$$

where: $\mathrm{N}$ is the number of diffraction peaks. The obtained values of $\mathrm{TC}_{\mathrm{hkl}}$ are gathered in Table 7. As we can see, the value of the largest texture coefficient with respect to all the films corresponds to the peak (012), which indicates that it is the preferred orientation. Hence, the peak (012) has the highest intensity when compared to the other peaks. The crystallites are predominantly parallel to the plane of the substrate.

Table 7. Texture coefficient $\left(T C_{h k l}\right)$ of NiS thin films prepared at diferent annealing time.

\begin{tabular}{|c|c|c|c|c|}
\hline Annealing time & (a): $0 \mathrm{~h}$ & (c): $1 \mathrm{~h}$ & (d): $2 \mathrm{~h}$ & (b): $3 \mathrm{~h}$ \\
\hline $\mathrm{TC}_{010}$ & 0,992 & 1,292 & 1,332 & 1,212 \\
\hline $\mathrm{TC}_{011}$ & 1,112 & 0,847 & 0,807 & 0,936 \\
\hline
\end{tabular}




\begin{tabular}{|l|l|l|l|l|}
\hline $\mathrm{TC}_{012}$ & 1,385 & 1,444 & 1,540 & 1,383 \\
\hline $\mathrm{TC}_{110}$ & 0,509 & 0,415 & 0,318 & 0,466 \\
\hline
\end{tabular}

The average crystallites size $\prec D \succ$, average micro-stress $\prec \varepsilon \succ$ and the average dislocation density $\prec \delta \succ$ of the films, can be determined using the formulas below [19,21,22]:

$$
\begin{gathered}
\langle D\rangle=\frac{\sum T C_{h k l^{*} D_{h k l}}}{n} \\
\langle\varepsilon\rangle=\frac{\sum T C_{h k l^{*} \varepsilon_{h k l}}}{n} \\
\langle\delta\rangle=\frac{\sum T C_{h k l} * \delta_{h k l}}{\sum T C_{h k l}}
\end{gathered}
$$

Table 8. The average values of $D, \varepsilon$ and $\delta$ of NiS films prepared with Annealing time.

\begin{tabular}{|c|c|c|c|}
\hline Annealing time & $\prec D \succ(\mathrm{nm})$ & $\prec \varepsilon \succ\left(10^{-3}\right)$ & $\prec \delta \succ\left(10^{15}\right.$ lines $\left./ \mathrm{m}^{2}\right)$ \\
\hline (a): $0 \mathrm{~h}$ & 16.498 & 7.330 & 4,336 \\
\hline (c): $1 \mathrm{~h}$ & 20.391 & 6.369 & 3,703 \\
\hline (d): $2 \mathrm{~h}$ & 23.584 & 4.967 & 1,951 \\
\hline (b): $3 \mathrm{~h}$ & 19.145 & 6.027 & 2,848 \\
\hline
\end{tabular}

It is evident that the micro-stress and the dislocation density decrease with increasing annealing time, inferring the formation of high quality thin films [23]. Acoordingly, the average crystallites size increases. This may be due to the fact that small crystallites are consumed during crystallization. Whereas, the dislocations acquire more energy and exhibit higher mobility. These dislocations that are activated segregate towards the boundaries of grains and are neutralized as the crystallization of the film proceeds [24]. According to these results shown in Table 8, it can be observed that the grain size increased with the increase in annealing time, bearing in mind that the increase in crystallite size in the samples is accompanied by an improvement in their electrical and optical properties as shown in Figure III.8.

\subsection{Optical properties}

Fig.2. indicates the transmittance spectra obtained for $\mathrm{NiS}$ at various annealing time. We notice that the transmittance rises with the wavelength increase and also increases with the annealing increase, owing to a rise in the thickness of deposited films. Because in the case of thicker films, there are more atoms in the films, and therefore there will be more cases of absorption of photons. We have found that the average optical transmittance for the deposited films is $0.56,2.48,5.63$ and $6.09 \%$ for the films prepared at the following annealing time respectively: $0 \mathrm{~h}, 1 \mathrm{~h}, 2 \mathrm{~h}$ and $3 \mathrm{~h}$. 


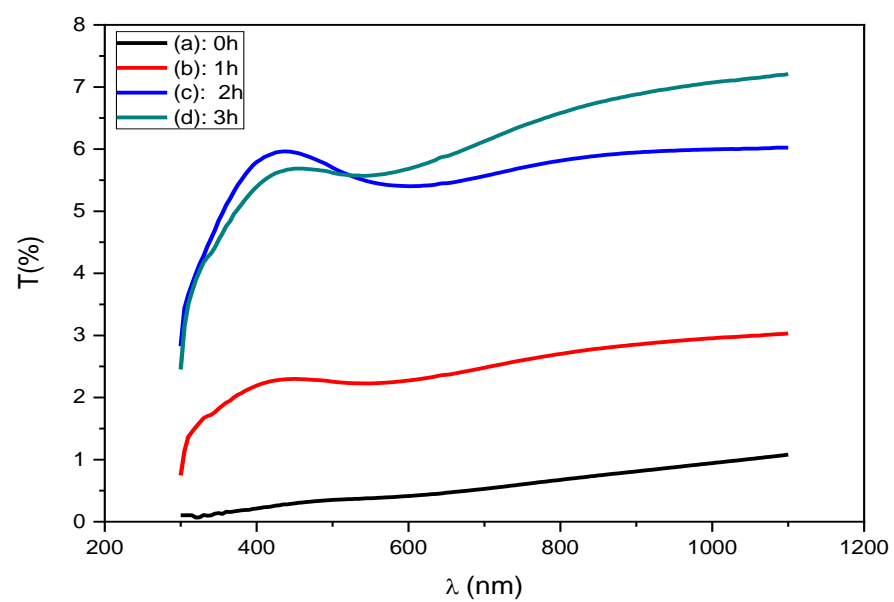

Fig. 2. Transmittance spectra of the NiS films: $(a): 0 h,(b): 1 h,(c): 2 h$ and $(d): 3 h$.

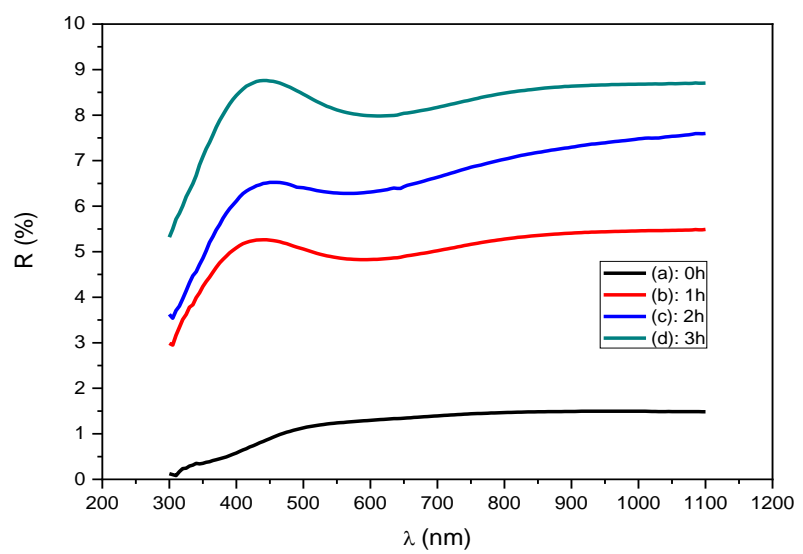

Fig. 3. Reflectance spectra of the NiS films: $(a): 0 h,(b): 1 h,(c): 2 h$ and $(d): 3 h$.

Fig.3. shows the reflection spectra of NiS films prepared in different annealing times $0 \mathrm{~h}$, $1 \mathrm{~h}, 2 \mathrm{~h}$ and $3 \mathrm{~h}$. The figure indicates that the reflection increases with the annealing time increasing, owing to a rise in the thickness of deposited films. Because in the case of thicker films, there are more atoms in the films, and therefore there will be more cases of absorption of photons [25], and we have found that the average optical reflection of deposited films is 1.21, 5.06, 6.61 and $8.25 \%$ films prepared at annealing time of $0 \mathrm{~h}, 1 \mathrm{~h}, 2 \mathrm{~h}$ and $2 \mathrm{~h}$, respectively.

We also notice on the spectra of the reflectance that the value of the reflectance is always higher than the value of the transmittance, this phenomenon can be related to a metallic behavior, which reflects the absorbent character of the nickel sulfide film [3, 26].

From the transmittance and reflectance spectrum, the absorption coefficient $(\alpha)$ can be obtained from relation (10) [19].

$$
\alpha=\frac{1}{\mathrm{e}} \ln \left(\frac{(1-\mathrm{R})^{2}}{\mathrm{~T}}\right)
$$

where: $\mathrm{e}$ is the film thickness, $\mathrm{T}$ is the transmittance, $\mathrm{R}$ is reflectance. In Fig. 4 . We present the absorption coefficient variation $(\alpha)$ as a function of wavelength $(\lambda)$ of deposited NiS films. We note a decrease in the value average of the absorption coefficient from $3.27 \times 10^{4}, 2.59 \times 10^{4}$, $2.20 \times 10^{4}$ to $2.19 \times 10^{4} \mathrm{~cm}^{-1}$ for annealing time of $0,1,2$ and $3 \mathrm{~h}$, respectively. This decrease can be correlated with improved crystal growth in NiS films by increasing annealing time, removal of defects and reduction in the number of grain boundaries. Moreover, the absorption coefficient values are close to the values of the literature [27]. 


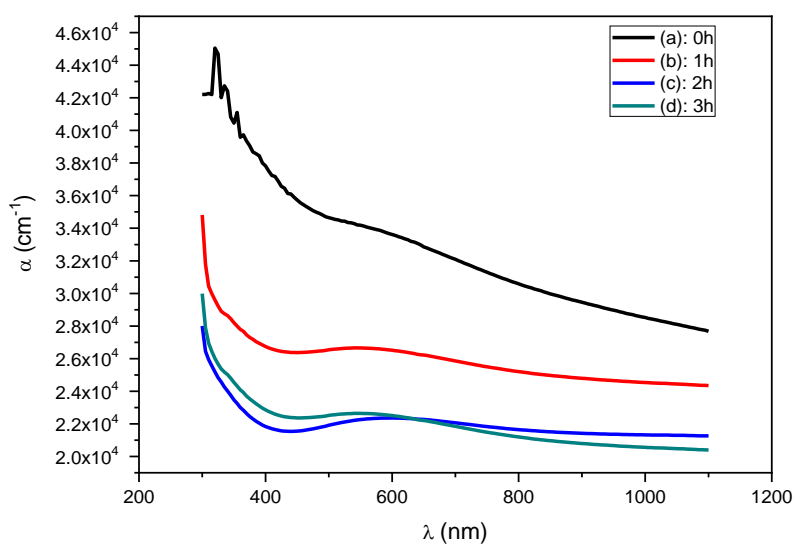

Fig. 4. Evolution of the absorption coefficient $(\alpha)$ of the NiS films: $(a): 0 h,(b): 1 h,(c): 2 h$ and $(d): 3 h$.

The average value of absorption coefficient $\left(\langle\delta\rangle>10^{4} \mathrm{~cm}^{-1}\right)$ for the films also supports the direct band gap nature of the film [27]. The films under study have an absorption coefficient $(\alpha)$ obeying the below relation for energies of high photon (hv) [28]:

$$
\alpha h v=B\left(h v-E_{g}\right)^{p}
$$

where: $\mathrm{B}$ is a constant; $\mathrm{p}$ is an integer which takes the value of $1 / 2$ or 2 for the direct or indirect transitions, respectively. Fig. 5 shows the curves $(\alpha h v)^{2}$ versus energy $(h v)$ for NiS thin films prepared at different annealing times $0 \mathrm{~h}, 1 \mathrm{~h}, 2 \mathrm{~h}$ and $3 \mathrm{~h}$.

As seen in Fig. 5, a remarkable decrease in energy gap from $1.25 \mathrm{eV}-1.01 \mathrm{eV}$ was noticed by raising the annealing time from $0 \mathrm{~h}$ to $3 \mathrm{~h}$, such a decrease may be due to the enhanced crystallinity with annealing time that resulted in the band gap that is optical varies with nickel to sulfur ratio in the structure leading to the change in the energy band structure, the states density (DOS) of the conduction band and the valence band [29]. 

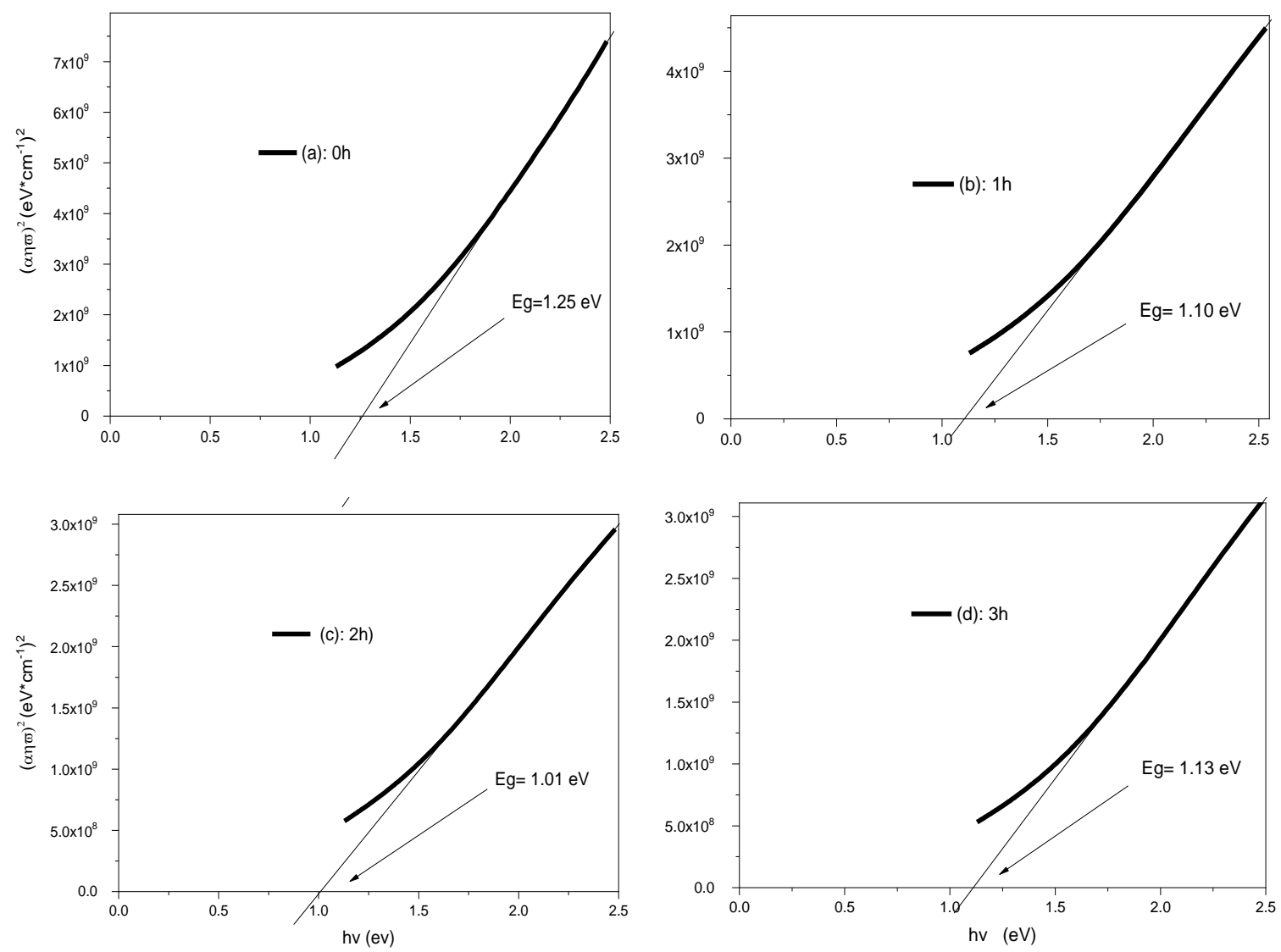

Fig. 5. $(a h v)^{2} v s . h v$ of the nanostructured NiS films: $(a):$ Oh, $(b): 1 h,(c): 2 h$ and $(d): 3 h$.

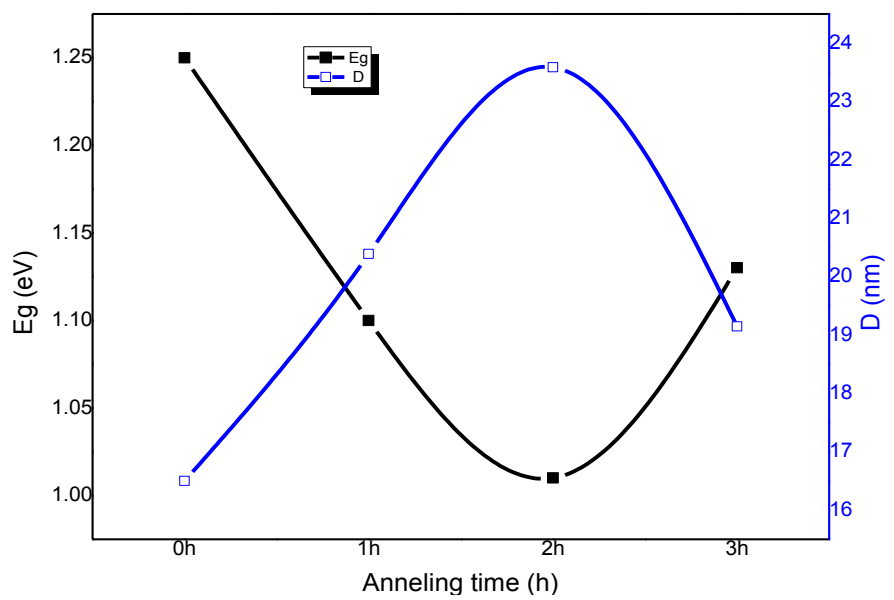

Fig. 6. Variation of the optical gap (Eg) and the grain size (D) as a function of the annealing time of the NiS films.

\subsection{SEM \& EDS}

Figure 7 shows the surface morphology of NiS thin films deposited by the spray pyrolysis technique at substrate temperature $300{ }^{\circ} \mathrm{C}$ without annealing and annealed at $300{ }^{\circ} \mathrm{C}$ at different annealing times $0 \mathrm{~h}, 1 \mathrm{~h}, 2 \mathrm{~h}$ and $3 \mathrm{~h}$.

From the SEM images of NiS deposited by the spray technique. We observed that the surface morphology of a NiS thin film deposited before annealing is fully covered, uniform and homogeneous and fuzzy. However, after annealing, the morphology of the layers that have not 
undergone a thermal treatment reveals a difference in contrast between the unannealed film and annealed at $1 \mathrm{~h}$ and $2 \mathrm{~h}$ but in the time of annealing $3 \mathrm{~h}$ it is noticed that the layer is darker, there are explosions of bubbles accompanied by ejection of material, this indicates that there is a formation in volume of a gas during the growth of the film which causes the emergence of bubbles on the surface, probably caused by the volatility of sulfur.

(a)
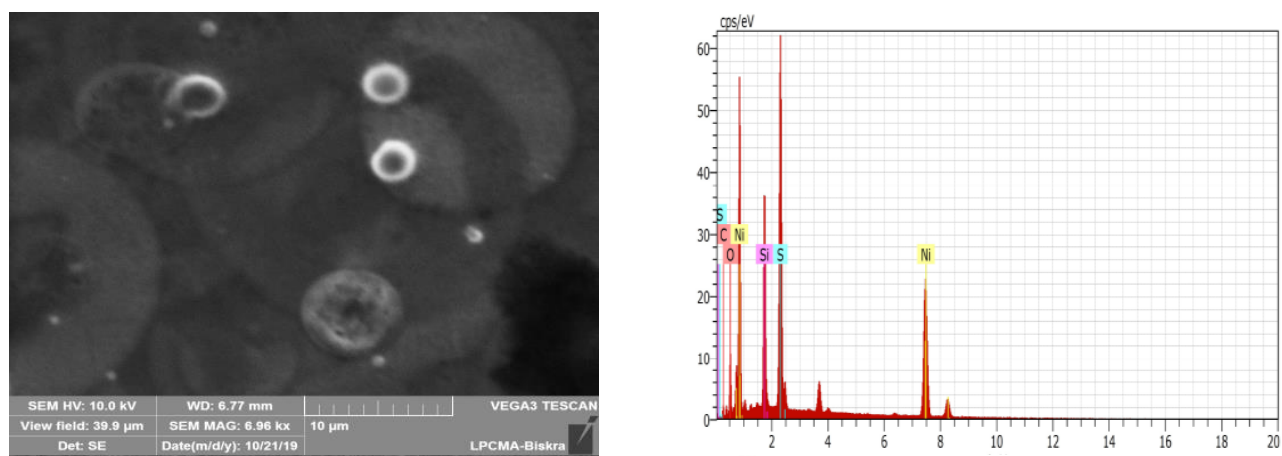

(b)

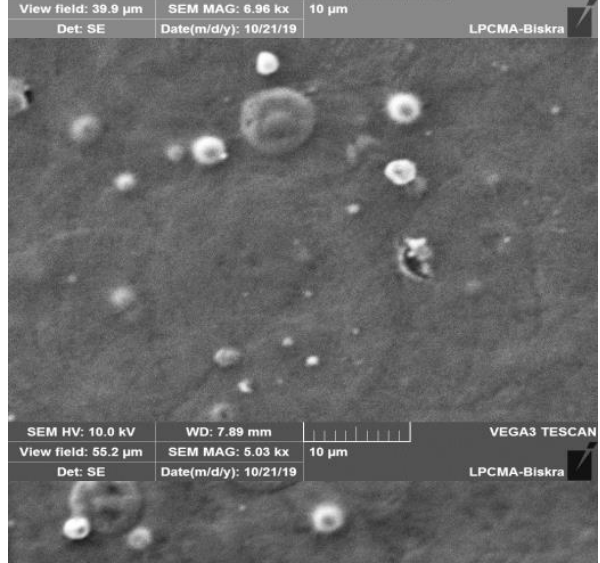

(c)
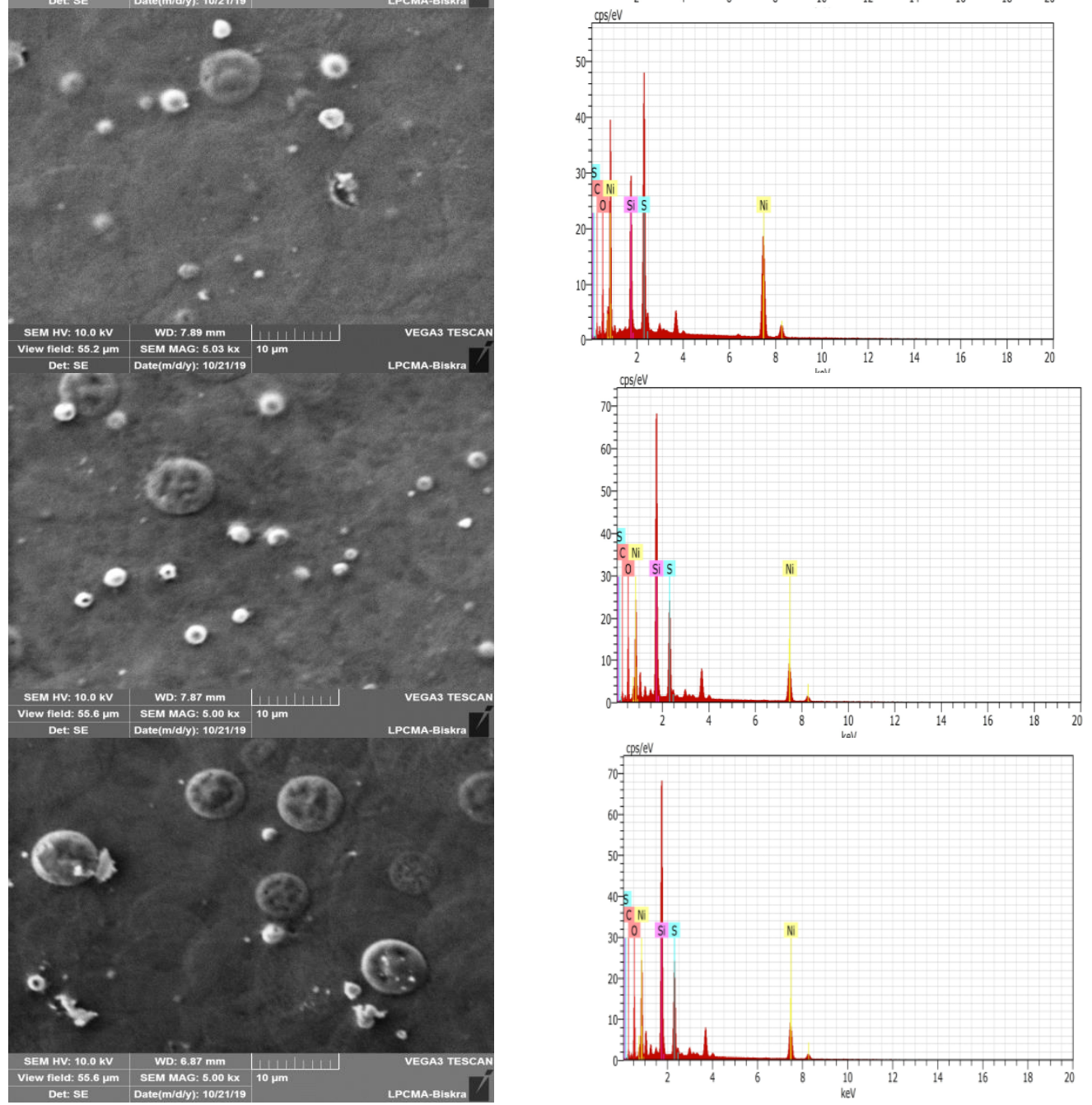

(d)

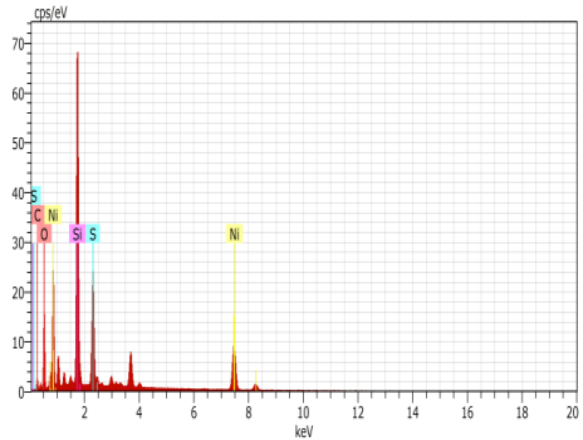

Fig. 7. SEM and EDS images for NiS thin films with different annealing times: (a) Oh, (b) $1 \mathrm{~h}$, (c) $2 h$ and (d) $3 h$. 
The EDS spectra of the films confirm the two elements Ni and S presence with different annealing time. Furthermore, the analysis showed the presence of other elements in the spectra such as oxygen $(\mathrm{O})$ and silicon $(\mathrm{Si})$ which originate from the $\mathrm{SiO}_{2}$ glass substrate. While the presence of carbon $\mathrm{C}$ is probably due to thiourea $\left(\mathrm{SC}\left(\mathrm{NH}_{2}\right)_{2}\right)$ involved in the synthesis. It is observed that the atomic percentage of sulfur decreases with the increase of the annealing time, we noted that the rate of sulfur is lower than that of nickel because sulfur is more volatile than nickel. Table. 9 summarizes the elementary analysis results.

Table 9. Elementary analysis of NiS thin films.

\begin{tabular}{|c|c|c|c|c|c|c|}
\hline Annealing time & $\mathrm{Ni}($ at. \%) & $\mathrm{S}($ at. \%) & $\mathrm{C}$ (at. \%) & $\mathrm{O}$ (at. \%) & $\mathrm{Si}($ at. \%) & (Ni/S) (\%) \\
\hline$(a):$ Oh & 23,79 & 21,59 & 20,85 & 21,73 & 12,05 & 1.10 \\
\hline$(b): 1 h$ & 21,48 & 17,91 & 20,24 & 29,96 & 10,41 & 1.19 \\
\hline$(c): 2 h$ & 18,47 & 16,24 & 26,17 & 25,42 & 25,42 & 1.13 \\
\hline$(d): 3 h$ & 10,33 & 9,28 & 32,92 & 26,23 & 21,24 & 1.11 \\
\hline
\end{tabular}

\subsection{Electrical properties}

The electrical conductivity of NiS films is important for their application in supercapacitors. The electrical measurements of these films were made by the four point's technique. In table 10 we have reported the values of the square resistance (Rsh), resistivity $(\rho)$ and conductivity $(\sigma)$ measured from the four-point technique according to the following conditions. Plate shape: square, Insert size: $76.1 \mathrm{~mm}$, Edge exclusion: $20 \mathrm{~mm}$, Number of points: 4 points, Current used: $2.5312 \mathrm{~mA}$.

The electrical conductivity of thin layers of NiS, it is based on the measured resistance of the sheet of the layers, as expressed [28].

$$
\begin{aligned}
& R_{S h}=\frac{\pi}{\ln 2} \times \frac{V}{I} \\
& \sigma=\frac{1}{\rho}=\frac{1}{e \times R_{S h}}
\end{aligned}
$$

Table 10. Values of $R_{s h}, \rho$ and $\sigma$ of non-annealed and annealed NiS film $1 \mathrm{~h}, 2 \mathrm{~h}$ and $3 \mathrm{~h}$.

\begin{tabular}{|c|c|c|c|}
\hline annealing time & $\mathrm{R}_{\mathrm{sh}}\left(10^{-1} \Omega / \mathrm{sq}\right)$ & $\rho\left(10^{-5} \Omega . \mathrm{cm}\right)$ & $\sigma 10^{4}(\Omega . \mathrm{cm})^{-1}$ \\
\hline (a): $0 \mathrm{~h}$ & 1.63 & 2.81 & 3.56 \\
\hline (b): $1 \mathrm{~h}$ & 1.14 & 1.76 & 5.67 \\
\hline (c): $2 \mathrm{~h}$ & 8.28 & 1.26 & 7.91 \\
\hline (d): $3 \mathrm{~h}$ & 1.19 & 2.01 & 4.97 \\
\hline
\end{tabular}


From the values recorded in Table 10, it can be seen that the conductivity increases according to the increase in the annealing time $(0 \mathrm{~h}, 1 \mathrm{~h}$ and $2 \mathrm{~h})$. This conductivity value increase is explained by the increase in the size of the crystallites with an increase in the annealing time, because when the size of the crystals is large, the areas between the crystals will be small. At the level of these, there are complete bonds between the atoms, which stimulate the reduction of a large number of defects which are traps for free charges. These results obtained are close to the values found by the researcher [30,31], Then at the time of 3 hours of annealing, we see that the conductivity drops to the value $4.97 * 10^{4}(\Omega . \mathrm{cm})^{-1}$. The electrical conductivity decrease with the annealing time increase because of the increasing of the disorder in the films; consequently, the potential barriers are increased $[32,33]$ because the introduced atoms are segregated into the grain boundaries. These results are supported by DRX and EDS results as shown in Figure 8. These results suggest that the films prepared by the spray pyrolysis technique behave like a metal, which is evident from the results of the very high conductivity that exceeds $10^{4}(\Omega . \mathrm{cm})^{-1}$.

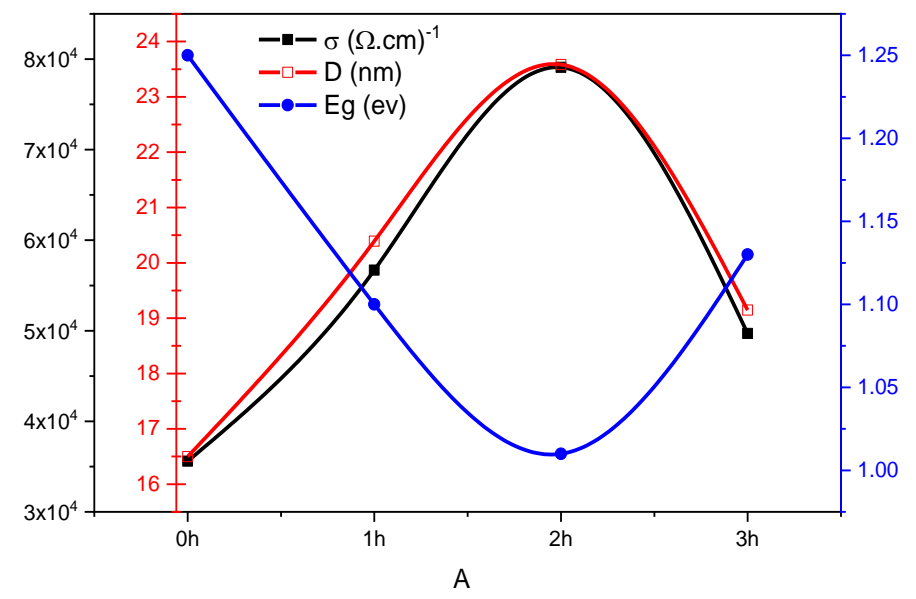

Fig. 8. Variation of conductivity, crystallite size and band gap of NiS films as a function of annealing time: $O h, 1 h, 2 h$ and $3 h$.

\section{Conclusion}

In this work we focused on the effect of annealing time on the morphological, optical, structural and electrical properties of nickel sulfide (NiS) thin films composed by spray pyrolysis deposited on glass substrates at the temperature of $300^{\circ} \mathrm{C}$. Then, we discuss thermally treated in a temperature oven $300{ }^{\circ} \mathrm{C}$ at different times of $1 \mathrm{~h}, 2 \mathrm{~h}$ and $3 \mathrm{~h}$. The diffraction of $\mathrm{X}$-ray results indicated that the deposited NiS thin films are single-phase and polycrystalline, having the hexagonal structure with high intense peaks at the (012) orientations. The crystallite size was found to increase with increasing annealing time from 16.49 to $23.58 \mathrm{~nm}$. The analysis of the optical properties showed that the band gap decreases from 1.25 to $1.01 \mathrm{eV}$ for the $0 \mathrm{~h}, 1 \mathrm{~h}, 2 \mathrm{~h}$, and $3 \mathrm{~h}$ annealing time, respectively. The coefficient order of the optical absorption is $10^{4} \mathrm{~cm}^{-1}$. The elemental composition analysis revealed that the atomic concentration of sulphur decreased with increasing annealing time. The SEM analysis showed that nanometer-sized spherical grains covering the entire surface of the films. Conductivity measurements through a four-point device showed that the conductivity increased with increasing annealing time from $\left(3.56 * 10^{4}\right.$ to $7.91 * 10^{4}$ $(\Omega . \mathrm{cm})^{-1}$. The results obtained have shown that the prepared NiS films contain good crystallization, dense morphology, good stochiometric ratio and high conductivity, and these specifications make them a potential candidate as electrode material for application in supercapacitors. 


\section{Acknowledgments}

Authors would like to thank Mr. Bali Hicham, a translator and a teacher of foreign languages for his help in writing this article.

\section{References}

[1] S. H. Yu, M. Yoshimura, Advanced Functional Materials 12(4), 277 (2002) ; https://doi.org/10.1002/1616-3028(20020418)12:4<277::AID-ADFM277>3.0.CO;2-M

[2] Y. Zhang, Z. Peng, S. Guan, X. Fu, Data in brief 16, 828 (2018) ; https://doi.org/10.1016/j.dib.2017.12.016

[3] A. Gahtar, S. Benramache, A. Ammari, A. Boukhachem, Annals of West University of Timisoara-Physics 63(1), 1(2021) ; https://doi.org/10.2478/awutp-2021-0001

[4] S. Suresh, S. S. Anand, R. Arul, D. Isha, Chalcogenide Letters 13(7), 291 (2016).

[5] A. Patil, A. Lokhande, P. Shinde, J. Kim, C. Lokhande, Journal of energy chemistry 27(3), 791 (2018) ; https://doi.org/10.1016/j.jechem.2017.05.005

[6] S. Sartale, C. Lokhande, Materials Chemistry and Physics 72(1), 101 (2001) ; https://doi.org/10.1016/S0254-0584(01)00314-5

[7] R. K. Singh, J. Narayan, Physical Review B 41(13), 8843 (1990) ; https://doi.org/10.1103/PhysRevB.41.8843

[8] H. Ruan, Y. Li, H. Qiu, M. Wei, Journal of Alloys and Compounds 588, 357 (2014) ; https://doi.org/10.1016/j.jallcom.2013.11.070

[9] P. Yang, M. Lü, C. F. Song, G. Zhou, D. Xu, D. R. Yuan, Journal of Physics and Chemistry of Solids 63(11), 2047 (2002) ; https://doi.org/10.1016/S0022-3697(02)00192-0

[10] V. P. Patil, S. Pawar, M. Chougule, P. Godse, R. Sakhare, S. Sen, P. Joshi, Journal of Surface Engineered Materials and Advanced Technology 01(02), 35 (2011); https://doi.org/10.4236/jsemat.2011.12006

[11] R. Karthikeyan, (2015).

[12] A. Ammari, M. Trari, B. Bellal, N. Zebbar, Journal of Electroanalytical Chemistry 823, 638

(2018); https://doi.org/10.1016/j.jelechem.2018.06.045

[13] V. Kumar, D. Sharma, K. Sharma, D. Dwivedi, Optik 156, 43 (2018) ;

https://doi.org/10.1016/j.ijleo.2017.10.169

[14] B. Bharathi, S. Thanikaikarasan, P. Chandrasekar, P. Kollu, T. Mahalingam, L. Ixtlilco, Journal of New Materials for Electrochemical Systems 17(3), 167 (2014) ;

https://doi.org/10.14447/jnmes.v17i3.417

[15] W. Chen, Y. Ning, Q. Li, K. Li, X. Wu, W. Wu, H. Zhang, Materials Letters XX, XXX (2018).

[16] M. Patel, I. Mukhopadhyay, A. Ray, Journal of Alloys and Compounds 619, 458 (2015) ; https://doi.org/10.1016/j.jallcom.2014.08.207

[17] C. Zaouche, Y. Aoun, S. Benramache, A. Gahtar, Scientific Bulletin of'Valahia'UniversityMaterials \& Mechanics 17(17) (2019) ; https://doi.org/10.2478/bsmm-2019$\underline{0015}$

[18]. A. Gahtar, A. Rahal, B. Benhaoua, S. Benramache, Optik 125(14), 3674 (2014) ; https://doi.org/10.1016/j.ijleo.2014.01.078

[19] R. Boughalmi, A. Boukhachem, M. Kahlaoui, H. Maghraoui, M. Amlouk, Materials Science in Semiconductor Processing 26, 593 (2014) ; https://doi.org/10.1016/j.mssp.2014.05.059

[20] A. Gahtar, S. Benramache, A. Ammari, A. Boukhachem, A. Ziouche, Inorganic and NanoMetal Chemistry 52(1), 112(2022); https://doi.org/10.1080/24701556.2020.1862225

[21] C. Buchmaier, M. Glänzer, A. Torvisco, P. Poelt, K. Wewerka, B. Kunert, K. Gatterer, G. Trimmel, T. Rath, Journal of Materials Science 52(18), 10898 (2017) ; https://doi.org/10.1007/s10853-017-1265-5 
[22] A. Ammari, M. Trari, N. Zebbar, Materials Science in Semiconductor Processing 89, 97

(2019) ; https://doi.org/10.1016/j.mssp.2018.09.003

[23] W. Eidelloth, R. Sandstrom, Applied physics letters 59(13), 1632 (1991) ;

https://doi.org/10.1063/1.106253

[24] N. K. Reddy, K. Ramesh, R. Ganesan, K. R. Reddy, K. Gunasekhar, E. Gopal, Applied Physics A 83(1), 133 (2006) ; https://doi.org/10.1007/s00339-005-3475-y

[25] K. Z. Yahiya, A. H. Jraiz, U. M. Nayef, Engineering and Technology Journal 26(7), 824 (2008).

[26] A. Gahtar, S. Benramache, C. Zaouche, A. Boukacham, A. Sayah, Advances in Materials Science 20(3), 36 (2020) ; https://doi.org/10.2478/adms-2020-0015

[27] A. Hammad, Z. Elmandouh, H. Elmeleegi, Acta Physica Polonica A 127(4), 901 (2015); https://doi.org/10.12693/APhysPolA.127.901

[28] A. Gahtar, S. Benramache, B. Benhaoua, F. Chabane, Journal of Semiconductors 34(7), 073002 (2013) ; https://doi.org/10.1088/1674-4926/34/7/073002

[29] S. Gedi, V. R. M. Reddy, C. Park, J. Chan-Wook, R. R. KT, Optical Materials 42, 468 (2015) ; https://doi.org/10.1016/j.optmat.2015.01.043

[30] M. G. Townsend, R. Tremblay, J. L. Horwood, L. J. Ripley, Journal of Physics C: Solid State Physics 4, 598 (1971); https://doi.org/10.1088/0022-3719/4/5/010

[31] J. Ray, M. Patel, P. Ghediya, TapasKChaudhuri, Mater. Res. Express 3, XXX (2016) ; https://doi.org/10.1088/2053-1591/3/7/075906

[32] A. Mosbah, M. Aida, Journal of Alloys and Compounds 515, 149 (2012) ;

https://doi.org/10.1016/j.jallcom.2011.11.113

[33] M. Lucio-Lopez, M. Luna-Arias, A. Maldonado, M. d. 1. L. Olvera, D. Acosta, Solar Energy Materials and Solar Cells 90(6), 733 (2006) ; https://doi.org/10.1016/j.solmat.2005.04.010 